\title{
Correction: Das Problem der Generationen
}

\section{Von Karl Mannheim}

\section{Institut für Soziologie und Sozialpsychologie}

Online publiziert: 11. Januar 2018

(C) Springer Fachmedien Wiesbaden GmbH, ein Teil von Springer Nature 2018

\section{Correction:}

Köln Z Soziol 2017

https://doi.org/10.1007/s11577-017-0412-y

Der Artikel „Das Problem der Generationen“ von Karl Mannheim, wurde mit dem falschen Titel auf unserem Internetportal Springer Link veröffentlicht.

Die Seite wurde korrigiert.

Die Online-Version des Originalartikels ist unter https://doi.org/10.1007/s11577-017-0412-y zu finden.

Institut für Soziologie und Sozialpsychologie $(\bowtie)$

Universität zu Köln

Lindenburger Allee 15, 50931 Köln, Deutschland

E-Mail: volker.dreier@uni-koeln.de 